\title{
Türkiye'de Domates Üretimi, Dış Ticareti ve Rekabet Gücü
}

\section{İsmail GÜVENÇ (iD}

Kahramanmaraş Sütçü İmam Üniversitesi, Ziraat Fakültesi, Bahçe Bitkileri Bölümü, Kahramanmaraş, Türkiye

$\bowtie$ : guvencis@hotmail.com

\section{ÖZET}

Bu çalışmada Türkiye'de toplam sebze üretiminde önemli paya sahip olan domatesin üretimi, dış ticareti ve rekabet gücü incelenmiştir. Türkiye'de 2017 verilerine göre 30 milyon tondan daha fazla sebze üretilmiştir. Toplam sebze üretiminin yaklaşık olarak \% 40-45'ini domates oluşturmaktadır. Dünya domates üretiminin \% $7.2^{\prime} \mathrm{i}$ Türkiye'de üretilmektedir. Türkiye domates üretiminin yıllara göre az çok farklılıklar olmakla birlikte \% 68-72'i açıkta, \% 28-32'i ise örtüaltında yapılmaktadır. toplam sebze ihracatımız sırasıyla 1.076,9 ve $1.268,0$ bin ton olarak gerçekleştirilmiştir. Bu verilere göre toplam sebze üretim miktarımızın $\% \quad 4$ kadarı ihracatta değerlendirilmektedir. Türkiye'nin toplam taze sebze ihracatı yaklaşık olarak 1,1 milyon ton'dur. Bu verilere göre Türkiye'nin toplam sebze üretiminin \% 4 kadarı ihraç edilmektedir. Diğer yandan ülkemiz domates ihracatında avantaja ve rekabet gücüne sahiptir.
Makale Tarihçesi

Geliş Tarihi: 06.08.2018

Kabul Tarihi : 03.09.2018

\section{Anahtar Kelimeler}

Sebze,

domates,

ihracat,

rekabet gücü

\section{Araştırma Makalesi}

\section{The Production, Foreign Trade and Competition Power of Tomatoes in Turkey}

\section{ABSTRACT}

In this study, the production, foreign trade and competition power of tomatoes, which has a significant share in the total vegetable production in Turkey, were evaluated. According to 2017 data, more than 30 million tons of vegetables were produced in Turkey. Tomato has approximately a share $40-45 \%$ of total vegetable production of this country. Turkey has $7.2 \%$ of world tomatoes production. In Turkey, approximately $68-72 \%$ of tomato is produced in the open-field and 28 $32 \%$ in protected cultivation. Total exports of fresh vegetables in Turkey is about 1.1 million tons. According to this, about $4 \%$ of the total vegetable production is exported from Turkey. On the other hand, Turkey has a significant advantages and competition power in the export of tomato.

\section{Article History \\ Received : 06.08.2018 \\ Accepted : 03.09.2018}

\author{
Keywords \\ Vegetable, \\ tomato, \\ export, \\ competition power
}

Research Article

To cite: Güvenç İ 2019. Türkiye'de Domates Üretimi, Dış Ticareti ve Rekabet Gücü. KSÜ Tar Doğa Derg 22(1) : 57-61, DOI : 10.18016/ksutarimdoga.vi.432316

\section{Gíiș}

Türkiye'de sebzeler iç pazar taleplerinin karşılanması, ihracata katkı yapması ve sanayiye hammadde sağlaması ile önemli bir tarımsal ürün grubudur. Türkiye'nin sebze üretiminde domates önemli bir paya sahiptir. Örneğin 2017'de Türkiye sebze üretiminin \% 41.4'ünü domates oluşturmaktadır (Çizelge 1 ve Şekil 1). Domatesin anavatanı Türkiye olmamakla birlikte ülkemizde domates çok yaygın olarak yetiştirilen bir sebze türüdür.

Domatesin anavatanı; Orta ve Güney Amerika'dır. Domates sözcüğü Güney Amerika'da yerlilerinin kullandığ 1 xitomate/zitotomate sözcügünden türe(til)miştir. Zehirli olduğunun düşünülmesi tüketimini ve yaygınlaşmasını geciktirmiştir. ABD'de 1800’lü yıllarda pişirilerek yemek olarak tüketilmeye başlanılmıştır. Anadolu'da ise 150 yıldır tanınmaktadır. Osmanlı İmparatorluğu döneminde ilk olarak Halep'e getirilmiştir. Buradan güney bölgelerimize daha sonra da diğer bölgelere yayılmıştır. Günümüzde hemen hemen tüm bölgelerimizde yetiştirilmektedir (Güvenç, 2017).

Türkiye'de sebze üretimi ve iç ve dış pazarlarda değerlendirme durumu önceki çalışmalarımızda incelenmiştir (Alan ve Güvenç 1992; Güvenç ve Alan, 1994a ve b; Kaymak ve ark., 2005; Güvenç ve Kaymak, 2008). Bu incelemelerde ortaya konan ve günümüzde de geçerli olan durum üretilen sebzenin tamamının iç pazarlarda değerlendiril(e)memesidir. $\mathrm{Bu}$ nedenle sebzelerin üretimi yanında pazarlanması özellikle dış ticaret imkânları önemlidir. 
Sebzelerin Türkiye'nin sebze ihracatındaki karşılaştırmalı üstünlüklerini, uluslararası rekabet gücünü, ortaya koyan araştırma sayısı oldukça sinırlıdır. Türkiye'nin üretim ve ihracatına ağırlık verme(me)si rasyonel olan sebze türleri; 1993-2012 dönemini kapsayan bir araştırma ile karşılaştırmalı üstünlükler teorisi ve en uygun kaynak tahsisi doğrultusunda belirlenmiştir (Erkan ve ark., 2015). Yine Türkiye'nin, geleneksel ihraç tarım ürünlerinin çoğunda (incir, kuru üzüm, fındık, fıstık ve kuru kayısı) karşılaştırmalı üstünlüğünün var olduğu bildirilmektedir (Erkan, 2012b). Sinırlı sayıdaki çalışmalarda domatesin üretim, ihracat ve rekabet gücü incelenmiştir. $\mathrm{Bu}$ nedenlerle bu incelemede Türkiye'de açıkta ve örtüaltında sebze üretiminde önemli paya sahip olan domatesin üretimi, rekabet gücü ve dış ticareti değerlendirilmiştir.

\section{TOPLAM SEBZE ÜRETIMI}

Türkiye'de sebze üretimi düzenli olarak artmaktadır. Nitekim 2017 verilerine göre 30 milyon tondan fazla sebze üretimi gerçekleştirilmiştir (Çizelge 1). Türkiye'de nüfusunun 80,8 milyon (Anonim, 2018a) olduğu dikkate alındığında yılda fert başına $380 \mathrm{~kg}$ kadar sebze üretilmektedir. Yüksek miktarda olan toplam üretim miktarı iç pazar ihtiyacını fazlası ile karşılamaktadır. Gıda ve Orman Bakanlığı Bitkisel Üretim Genel Müdürlüğü ise Türkiye'nin sebze üretiminde kendine yeterliliğini $\% \quad 120$ olarak bildirmektedir (Anonim 2018b). Sebze türleri arasında domatesin yeterlilik durumunun yüksek olduğu değerlendirilmektedir. $\mathrm{Bu}$ fazla üretilen sebzenin pazarlanması en önemli sorundur (Güvenç ve Kaymak, 2008).

Sebze üretiminin \%82,5’ni meyvesi yenilen sebzeler oluşturmaktadır. Bu grup sebzelerde domates, biber, patlıcan, kavun ve karpuz üretimde önemli paya sahiptir. Bununla birlikte toplam sebze üretiminin \%40-45'ini sadece domatesin oluşturduğu da dikkate alınmalıdır (Çizelge 1 ve Şekil 1). Bu nedenle domatesin iç ve dış pazarlarda değerlendirilmesi üzerinde önemle durulmalıdır.

\section{DOMATES ÜRETIMI}

Dünyada domates üretimi ise 177 milyon tondur (Anonim 2018c). Türkiye dünya domates üretiminde 4. sirada ve \% 7.2'lik paya sahiptir. $\mathrm{Bu}$ durum Türkiye'nin domates üretiminde dünyada söz sahibi olduğunun ve dış ticaretinde geliştirilebilecek potansiyeli olduğunu göstermektedir.

Çizelge 1. Türkiye'de Toplam Sebze Üretimi ve Gruplara Dağılımı (Ton/Yıl).

\begin{tabular}{|l|c|c|c|c|c|}
\hline Sebze Grubu & 2016 & $\%$ & 2017 & $\%$ & Değişim ${ }^{(1)}(\%)$ \\
\hline Yumru ve köklüler & 3.399 .810 & 11.2 & 3.425 .820 & 11.1 & 0.8 \\
\hline Meyvesi Yenenler & 24.955 .248 & 82.5 & 25.430 .915 & 82.5 & 1.9 \\
\hline Baklagiller seb. & 892.26 & 2.9 & 884.798 & 2.9 & -0.9 \\
\hline Yaprağı Yenen & 1.621 .237 & 5.4 & 1.662 .145 & 5.4 & 2.5 \\
\hline Diğger Sebzeler & 290.602 & 0.9 & 306.689 & & 5.5 \\
\hline Toplam & 30.266 .897 & 100 & 30.825 .569 & 100 & 1.8 \\
\hline
\end{tabular}

Kaynak: Anonim 2018a; (1): 2016’ya göre 2017'deki artış ve azalışı göstermektedir; (2):Karnabahar, brokoli ve mantarın toplamını göstermektedir

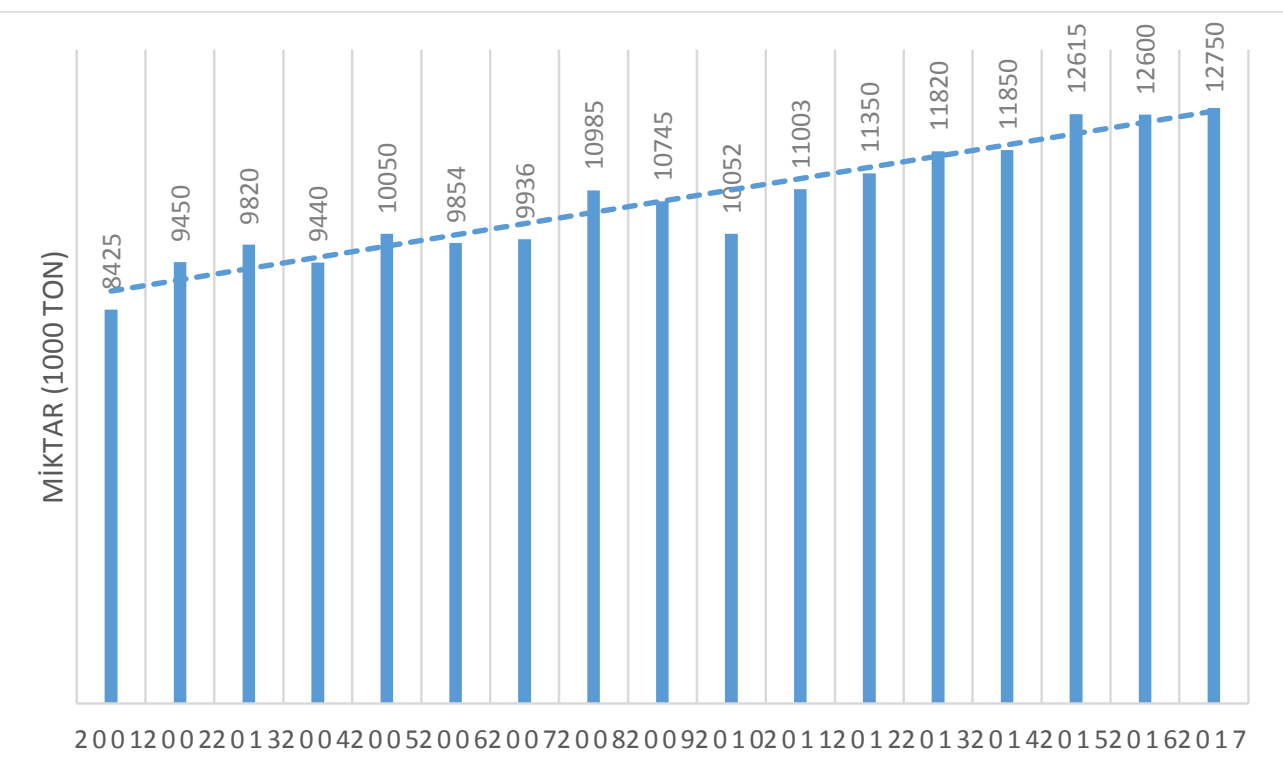

Şekil 1. Türkiye'de Domates Üretimindeki Değişim (Kaynak: Anonim 2018a) 
Türkiye'de taze domates üretimi açıkta ve seralarda, işleme sanayine hammadde olarak ise açıtata (tarlada) yapılmaktadır. Üretim miktarımız uzun yıllardan beri her yıl artmaktadır. Bu durumu domates üretiminin 2001'de 8.5 milyon ton kadar iken 2017'de \% 50 civarında artarak 12.75 milyon tona yükselmiş olması teyit etmektedir (Şekil 1). Domateste üretim artışının tarımsal girdi kullanımının iyileşmesi gibi faktörlerden kaynaklanabileceği ve 1960-1999 periyodunda domateste verimlilikte 2,16 katı artma olduğu belirlenmiştir (Kaymak ve ark., 2005). Girdi ve yeni tekniklerin domates üretiminde kullanılması ile verimlilik daha da artabilir. Son yıllarda örtüaltında domates yetiştiriciliğinin yaygınlaşması üretim ve verimliğin artması yanında sezon genişlemesini de sağlamıştır. Yüksek miktarda üretimi yapılan domatesin iç ve dış pazarlama imkânları mutlaka değerlendirilmedir. Farklı mevsimlerde iç ve dış pazarlarda domates bulundurulması Türkiye'nin rekabet şansını artıracaktır. Diğer yandan Türkiye'de domates üretimini gerek mevsiminde (açıkta) gerekse mevsim dışında (seracılık) artırmak mümkündür.

\section{ÖRTÜALTINDA DOMATES ÜRETIMI}

Türkiye'de örtüaltında toplam sebze ve domates üretimi Çizelge 2'de verilmiştir. Çizelge incelendiğinde de anlaşılacağı gibi 2001 yılında örtüaltında 3.6 milyon ton olan toplam sebze üretimi 2017 yllında 7.3 milyon tona yükselmiştir. Aynı yıllarda domates üretimi ise 1.4 milyon tondan 3.8 milyona yükselmiştir. Son 15 yılda örtüaltında toplam sebze üretimi \% 100, domates üretimi ise \% 170 oranında bir artış göstermiştir. Toplam örtüaltı sebze üretimi ve domates üretimindeki bu artış mevsim dışında da pazarlarda ürün bulundurma imkânı sağladığından önemsenmelidir.

Çizelge 2. Ülkemizde Örtüaltında Toplam Sebze ve Domates Üretimi (Ton/Yil).

\begin{tabular}{|c|c|c|c|}
\hline Yll & Toplam & Domates & Oran (\%) \\
\hline 2001 & 3.663 .338 & 1.417 .667 & 38.7 \\
\hline 2005 & 4.271 .525 & 2.023 .888 & 47.4 \\
\hline 2010 & 5.478 .566 & 2.852 .863 & 52.1 \\
\hline 2015 & 6.346 .770 & 3.394 .447 & 53.5 \\
\hline 2016 & 6.743 .085 & 3.614 .472 & 53.6 \\
\hline 2017 & 7.383 .880 & 3.829 .831 & 51.9 \\
\hline
\end{tabular}

Kaynak: Anonim 2018a

Türkiye'de tüketilen her 4 kilogram sebzenin yaklaşık 1 kilogramı seralarda üretilmektedir (Çizelge 1 ve 2). Örtüaltı sebze üretiminin \% 50'sini domates oluşturmaktadır (Çizelge 2). Bu verilere göre Türkiye domates üretiminin yıllara göre farklılıklar olmakla birlikte \% 70’i açıkta, \% 30’u ise örtüaltında yapıldığı anlaşılmaktadır.
Son ylllarda domates yılın her mevsiminde üretilen ve tüketilen bir sebze haline gelmiştir. Türkiye'de domates üretiminde en önemli üretici bölgeler sırasıyla Akdeniz, Ege ve Doğu Marmara'dır. Bu üç bölge toplam üretimin \% 69'unu karşılamaktadır. Ülkemiz domates üretiminde Akdeniz Bölgesi'nin payı ise \% 30.7'dir.

\section{TÜRKIYE'NİN DOMATESTE DIŞ TİCARETI}

Türkiye'de üretilen sebze miktarı iç pazar talebinden fazla olduğundan üretilen sebzenin dış pazarlarda değerlendirilmesi önem arz etmektedir. Akdeniz İhracatçı Birlikleri raporuna göre (Anonim 2017) 2016 ve 2017 'de toplam sebze ihracatımız sirasiyla 1.076,9 ve $1.268,0$ bin ton olarak gerçekleştirilmiştir. Bu verilere göre toplam sebze üretim miktarımızın (Çizelge 1) \% 4 kadarı ihracatta değerlendirilmektedir. Önceki yıllarda da yaptı̆̆ımız çalışmalarda üretilen sebzelerin \% 5 kadarının ihracatta değerlendirildiği belirlenmiştir (Güvenç ve Kaymak, 2008).

Sebze ihracatında domates önemli bir paya sahiptir. Domates dış ticarette taze ve işlenmiş olarak değerlendirilen ürünler arasındadır. Domates taze, salça ve soyulmuş domates olarak dış ticarette değerlendirilmektedir. Taze domates ihracat miktarı yıldan yıla değişmekle birlikte son $4-5$ yll dikkate alındığında 500 bin ton civarındadır (Çizelge 3).

Çizelge 3. Türkiye'nin Domates Dış Ticareti (Ton/Yıl).

\begin{tabular}{|c|c|c|c|}
\hline Yil & Taze & Salça & Soyulmuş Domates \\
\hline \multicolumn{4}{|c|}{ İhracat } \\
\hline 2012 & 560.430 & 85.172 & 13.423 \\
\hline 2013 & 483.046 & 111.515 & 11.397 \\
\hline 2014 & 585.202 & 140.798 & 15.615 \\
\hline 2015 & 541.355 & 118.639 & 12.379 \\
\hline 2016 & 485.963 & 142.662 & 16.662 \\
\hline 2017 & $526,1^{*}$ & - & - \\
\hline \multicolumn{4}{|c|}{ İthalat } \\
\hline 2012 & 132 & 252 & 4 \\
\hline 2013 & 51 & 288 & 46 \\
\hline 2014 & 107 & 349 & 42 \\
\hline 2015 & 494 & 740 & 47 \\
\hline 2016 & 787 & 306 & 16 \\
\hline
\end{tabular}

Kaynak: Anonim 2018c; (*)Anonim 2017'den alınmıştır

Nitekim Akdeniz İhracatçı Birlikleri (AKİB) raporunda da 2017 yılında 526.1 ton taze domates ihracatı gerçekleştirildiği bildirilmektedir. Buna göre toplam sebze ihracatında domatesin \% 50 civarında bir payı vardır. Bununla birlikte 1988-1990 döneminde sebze ihracatımızın \% 25 kadarını domatesin oluşturduğu tespit edilmiştir (Alan ve Güvenç, 1992; Güvenç ve Alan, 1994a). Bu durum domatesin sebze ihracatındaki payının artmakta olduğunu 
göstermektedir. Ancak Türkiye'nin toplam domates üretim miktarı (Şekil 1) dikkate alındığında domates üretimimizin $\% 5$ kadarının ihracatta değerlendirildiği anlaşılacaktır. $\mathrm{Bu}$ nedenle sebze/domates ihracatını daha da artırıcı önlemlere yer verilmelidir.

Domates taze ve işlenmiş olarak ithalatı da yapılan bir sebze türüdür. Son yıllarda salça ithalatının artma eğilimi vardır (Çizelge 3).

Sebze ihracatımız büyük oranda Ortadoğu, Avrupa ve Rusya pazarlarınadır. Taze sebze ihracatında 2017'de Rusya'nın ve Irak'ın payı sirasiyla \% 32 ve \% 26'dır (Anonim 2017). Geçmiş yıllarda sebze ihracatında Ortadoğu ülkelerinin payının \% 70-75 (Alan ve Güvenç, 1992; Güvenç ve Alan, 1994a) ve o zamanki adıyla Avrupa Ekonomik Topluluğu (AET) ülkelerinin (1993 yılından sonra Avrupa Birliği (AB) oldu) ise \% 21.3 payı (Güvenç ve Alan, 1994b) olduğu belirlenmiştir. Son yıllarda domates Irak'ta yaşanan iç savaş Türkiye'den bu ülkeye yapılan sebze ihracatını olumsuz yönde etkilemiştir. Yine Rusya ile Suriye'de uçak düşürülmesi sonrası yaşanan kriz domates ihracatımızı olumsuz yönde etkilemiştir. Bu örnekler bölgesel barışın tarımsal ürün (sebze) ticaretinde de ne kadar önemli olduğunu göstermektedir.

Karşılaştırmalı Üstünlük Teorisi'ne göre, bir ülke ticaret ortaklarina göre nispi olarak ucuza (daha düşük birim emek maliyetle) üretebildiği malları ihraç etmeli, nispi olarak pahalıya (daha yüksek birim emek maliyetle) üretebildiklerini de ithal etmelidir (Hajiyev, 2004). Farklı ülkelerin sebze ihracatında durumunu ortaya koymak için yapılan çalışmalarda Macaristan'ın karşılaştırmalı üstünlüğe sahip olduğu (Fertő ve Hubbard 2001); Slovenya'nın ise karşılaştırmalı üstünlüğünün olmadığı (Bojnec ve Fertő 2006) belirlemiştir. Bunun yanında Türkiye'nin sebzecilikte bazı alt grupların ihracatında küresel piyasalarda önemli bir karşılaştırmalı üstünlüğe sahip olduğu belirlenmiştir. Ancak, sebze alt gruplarının büyük çoğunluğunun ihracatında karşlaştırmalı üstünlük olmasına rağmen, son yıllardaki üstünlüklerde nispi olarak azalma da söz konusudur (Erkan ve ark., 2015). Bununla birlikte domateste "göreli ihracat avantajı indeksi" 2010 yılına göre azda olsa azalsa da hale yüksek bir seviyededir (Çizelge 3). Göreli İhracat Avantajı indeksi belirli bir üründe bir ülkenin dünya piyasalarında sahip olduğu ihracat payının diğer bütün mallarda dünya ihracatında sahip olduğu paya oranı olarak tanımlanabilir (Bashimov, 2016).

Üretimin miktarı ve yeterlilik oranı yüksek olan domatesin dış ticarette değerlendirilmesi önem arz etmektedir. Diğer yandan domatesin dış ticarette yeri incelenirken rekabet gücünün ne olduğunun bilinmesi başarı şansını artıracaktır.

\section{TÜRKIYE'NINN DOMATESTE REKABET GÜCÜ}

Sebzelerin dış ticarette rekabet gücünü belirlemek için yapılan bir çalışmada karşılaştırmalı üstünlük durumu iki dönemde (1993-2002 ve 2003-2012) incelenmiştir (Erkan ve ark., 2015). Çalışma sonunda sebzelerde dış ticarete konu olan 11 farklı ürün grubundan sadece domatesin ihracatta rekabet gücünün var olduğu ve artış gösterdiği tespit edilmiştir (Erkan ve ark., 2015). Benzer şekilde Türkiye'nin domateste ihracat performansı ve rekabet gücü başka bir araştırmada da belirlenmiştir (Bashimov, 2016). Bu araştırma sonucuna göre de Türkiye'nin domates ihracatında rekabet gücüne sahip olduğu ve incelenen yıllara göre değişmekle birlikte Türkiye'nin domates ihracatındaki rekabet gücünün giderek arttığı tespit edilmiştir (Çizelge 4). Çizelge 3 'deki indeks değeri 1'den büyükse o ülkenin ilgili sektörde karşlaştırmalı üstünlüğe sahip olduğu söylenir. Başka bir deyişle, o endüstrinin ülkenin toplam ihracatı içindeki payı, dünya ticaretindeki payından daha büyüktür. Eğer indeks değeri birden az ise ülkenin ilgili sektörde karşılaştırmalı dezavantaja sahip olduğu anlamina gelir (Bashimov, 2016).

Karşılaştırmalı üstünlük indeksi (RCAij/AKÜ) indeksi, bir ülkenin belirli bir mal, endüstri veya sektördeki karşılaştırmalı avantajını veya dezavantajını değerlendirmek için kullanılan bir yöntemdir. AKÜ indeksi, bir malın veya sektörün ülkenin toplam ihracatındaki payı ile söz konusu malın veya sektörün dünyanın toplam ihracatındaki payı arasındaki orandır (Bashimov, 2016).

Çizelge 4.Türkiye'nin Domateste Rekabet Gücü İndeks Değerleri (Karşılaştırmalı üstünlük indeksi (RCA) ve göreli ihracat avantajı indeksi (RXA)).

\begin{tabular}{|c|c|c|}
\hline Yll & RCA & RXA \\
\hline 2000 & 3.07 & 3.10 \\
\hline 2005 & 4.04 & 4.13 \\
\hline 2010 & 7.65 & 8.09 \\
\hline 2011 & 6.67 & 6.99 \\
\hline 2012 & 5.82 & 6.08 \\
\hline 2013 & 5.40 & 5.61 \\
\hline 2014 & 5.61 & 5.61 \\
\hline
\end{tabular}

Kaynak: Bashimov, 2016

Not: RXAij = j ülkesinin i malında göreli ihracat avantajını; RCAij (AKÜ) ‘j’ ülkesinin 'i’ sektörü için karşılaş̧tırmalı üstünlük indeksi

Domatesin rekabet gücü ile ilgili yapılan değerlendirmeler ise şu şekildedir (Bashimov, 2016): “Türkiye'nin domates ürünündeki rekabet gücü 2010 yılından bu yana gerilemektedir. Türkiye'nin en önemli ticari ortağı olan Rusya ve Avrupa ekonomilerinin son yıllarda zayıf bir büyüme trendi göstermesi sonucu Türkiye'nin bu pazarlara olan 
domates ihracatı azalmıştır. Dolayısıyla Türkiye'nin domates ihracatındaki rekabet gücü son yıllarda zayıflamaktadır."

$\mathrm{Bu}$ son analizler dikkate alındığında domates ihracatının genel politikalar çerçevesinde yeniden değerlendirilmesi gerekir. Türkiye ekonomisi acısından bölgesel barışın ne kadar önemli olduğu gerçeği bir kere daha ortaya çıkmaktadır.

\section{SONUC}

Standart Uluslararası Ticaret Sinıflandırması (SITC) faktör yoğunluğuna göre yapıldığında dünyada ihracatı yapılan ürün grupları hammadde yoğun, emek yoğun, sermaye yoğun, kolay taklit edilen ar-ge bazlı ve zor taklit edilen ar-ge bazlı olmak üzere beşe ayrılmaktadır (Erkan ve ark., 2015). Tarım ürünleri hammadde yoğun ürün grubu kapsaminda ele alınmaktadır. Türkiye'nin faktör yoğunluğuna göre ihracat rekabet gücü incelendiğinde emek ve sermaye yoğun malların ihracatında karşılaştırmalı üstünlüğe sahip olduğu görülmektedir (Erkan, 2012a). Diğer tarımsal ürünlerle karşılaştırıldığında sebzeler daha fazla emek yoğun ürünlerdir. $\mathrm{Bu}$ nedenle sebze türlerinde ihracat imkânları fazla olan ürünler üzerinde yoğunlaşmak gerekmektedir. Domates de bu ürünlerden biridir. Yapılan analizlere göre domates üretim, ihracat ve rekabet bakımından avantajlı bir sebzedir. $\mathrm{Bu}$ avantajın sürdürülebilir olması önemlidir. $\mathrm{Bu}$ nedenle domates üretiminin her aşamasında ulusal ve uluslararası pazarların standartlarını karşılamak için modern tekniklere yer verilmeli; taze olarak dış ticareti yanında katma değeri yüksek domatesten elde edilen mamul ürünler teşvik edilmelidir.

\section{KAYNAKLAR}

Anonim 2017. Akdeniz Yaş Meyve Sebze İhracatçıları Birliği (AKİB) Çalışma Raporu 2017, YenişehirMersin, S:22.

Anonim 2018a. Bitkisel Üretim İstatistikleri. TUIK, http://www.tuik.gov.tr/ PreTablo.do?alt_id=1001. Erişim Tarihi: 01.05.2018.

Anonim 2018b. Bitkisel Üretim İstatistikleri. Tarım ve Ormancılık Bakanlığı Bitkisel Üretim Genel Müdürlüğü (BUGEM), https://www.tarim.gov.tr/ BUGEM/ Menu/9/Veriler. ErişimTarihi: 03.04.2018

Anonim 2018c. Food and Agriculture Organization of the United Nations (FAO). FAOSTAT, http://www.
fao.org/faostat/en/\#data/QC. Erişim Tarihi: 11.05.2018.

Alan R, Güvenç İ 1992. Türkiye'nin Sebze İhracatına Genel Bir Bakış. Tarımda Kaynak Dergisi, 1 (1-2): 15-17.

Bashimov G 2016.Türkiye'nin Domates İhracat Performansı ve Rekabet Gücü. Alınteri Dergisi, 31(B) : 1-8.

Bojnec S, Fertő I 2006. Does Comparative Advantages in Agro-Food Trade Matter for Multifunctional Rural Development: The Case of Hungary and Slovenia. Journal of Central European Agriculture, 7(3): 583-586.

Erkan B, Arpacı BB, Yaralı F, Güvenç İ 2015. Türkiye'nin Sebze İhracatında Karşlaştırmalı Üstünlükleri. KSÜ Doğa Bil. Dergisi, 18(4): 70-76.

Erkan B 2012a. Türkiye'nin Geleneksel İhraç Tarım Ürünlerinde Uzmanlaşma Düzeyi. Sosyal ve Beşeri Bilimler Dergisi, 4(1):75-83.

Erkan B 2012b. BRIC Ülkeleri ve Türkiye'nin İhracat Uzmanlaşma ve Rekabet Düzeylerinin Karşılaştırmalı Analizi. Ekonomik ve Sosyal Araştırmalar Dergisi, 8 (1):101-131.

Fertő I, Hubbardn LJ 2001. Regional Comparative Advantage and Competitiveness in Hungarian AgriFood Sectors. 77th EAAE Seminar / NJF Seminar No. 325, August 17-18, Helsinki, p: 1-13.

Güvenç I, Kaymak HC 2008. Türkiye'de Sebze Üretimi ve Tüketimindeki Değişme, Gereksinim ve Projeksiyon. Alınteri, 15 (B): 40-45.

Güvenç İ, Alan, R 1994a. Türkiye'nin Orta Doğu Ülkelerine Sebze İhracatı. Atatürk Üniversitesi Ziraat Fakültesi Dergisi, 25, (2):269-274

Güvenç İ, Alan R 1994b. Türkiye'nin Avrupa Topluluğu Ülkelerine Sebze İhracatı. Atatürk Üniversitesi Ziraat Fakültesi Dergisi, 25, (1) :94-99.

Güvenç İ, 2017. Sebzecilik: Temel Bilgiler, Muhafaza ve Yetiştiricilik. Nobel Yayınları, S: 288.

Hajiyev NO 2004. Study of Azerbaijan's Current and Potential Comparative Advantage. Center of Economic Reforms Ministry of Economic Development-UNDP Azerbaijan, Baku, p:8

Kaymak HC, Güvenç İ, Dursun A, 2005. Türkiye'de Sebze Tarımının Mevcut Durumu, Önemli Bazı Gelişmeler ve Çözüm Önerileri. Atatürk Üniversitesi Ziraat Fakültesi Dergisi, 36 (2): 221228. 